\title{
Assessment of Clergy Knowledge and Attitudes Toward Near-Death Experiences
}

\author{
Lori J. Bechtel, Ph.D. \\ Alex Chen, Ph.D. \\ Richard A. Pierce, Ph.D. \\ Pennsylvania State University Altoona Campus
}

Barbara A. Walker, Ph.D.

Eastern Illinois University

ABSTRACT: The results of a questionnaire distributed to 2,722 clergy from Pennsylvania and Illinois ( 320 usable questionnaires returned) showed the respondents had limited knowledge of the near-death experience (NDE) but had a moderately positive attitude toward the subject. Using Nina Thornburg's (1988) Near-Death Phenomena Knowledge and Attitudes Questionnaire, respondents' mean score for knowledge questions was 7.8 out of 18 , and mean score for attitudes questions was 49 out of 85 . Approximately $98 \%$ of the clergy had heard of NDEs; $85 \%$ of the clergy had counseled parishioners who had had NDEs; nearly $40 \%$ had had personal contact with an experiencer; and $10 \%$ reported having had NDEs themselves. Respondents were most familiar with the near-death element of "peace," and with experiencers' greater appreciation for life and belief in an afterlife.

Lori J. Bechtel, Ph.D., is Assistant Professor of Health Education, Alex Chen, Ph.D., is Assistant Professor of Management Information Systems, and Richard A. Pierce, Ph.D., is Assistant Professor of Human Development at the Pennsylvania State University Altoona Campus. Barbara A. Walker, Ph.D., is Assistant Professor of Health Studies at Eastern Illinois University. Reprint requests should be addressed to Dr. Bechtel at the Department of Health Education, Pennsylvania State University Altoona Campus, 206A Adler Building, Altoona, PA 16601. 
Despite the attention near-death experiences (NDEs) have recently received, many people still cannot relate to the concept of an NDE, and often the experiencer's claims are discounted. David Royse (1985) reported that it is not rare for near-death accounts to be reported to the clergy and it is understandable that clergy often would be directly accessible to near-death experiencers immediately following near-fatal encounters. Little has been done in the way of researching this population and literature is scant regarding knowledge and attitudes of clergy concerning this topic. According to Kenneth Ring (1982), individuals merely exposed to information about NDEs develop a diminished fear of death and the change is particularly evident when direct contact is made with a near-death experiencer. Unfortunately, however, a number of NDErs encounter depressive aftereffects due to a lack of sensitivity and understanding on the part of those individuals who work closely with them following an NDE (Ring, 1984). Obviously, the needs of many near-death experiencers often are not being met. Since clergy are a likely population to come in contact with near-death experiencers immediately following an NDE, it would be beneficial to investigate their knowledge and attitudes regarding this topic.

The purpose of the current investigation was to determine the knowledge and attitudes of clergy toward near-death phenomena. Secondary purposes of this study were (a) to determine how many of these clergy had been confronted by parishioners who claimed to have had an NDE, (b) to determine how many clergy have themselves undergone an NDE, and (c) to compare clergy knowledge of the NDE based on geographical location, religious denomination, educational background, and previous exposure to a friend or family member's NDE.

\section{Methods}

\section{Participants}

The population sampled for this study was drawn from a four-county area in Pennsylvania and a four-county area in Illinois. Using the Roper data bank, all counties in Illinois and Pennsylvania were analyzed considering population, median income, poverty level, unemployment, and percent urban income, agriculture, manufacturing, and labor force. Subsequently, two urban counties (Lake and DuPage) and two rural counties (Woodford and Iroquois) in Illinois were matched with two urban counties (Montgomery and Delaware) and two rural 
counties (Snyder and Wayne) in Pennsylvania. Clergy of all denominations $(\mathrm{N}=2,722)$ in each county were identified through the American Church List, Inc. All clergy members in the eight counties were invited to participate in the study.

\section{Instrument}

To determine the knowledge and attitudes of clergy toward near-death phenomena, Nina Thornburg's (1988) Near-Death Phenomena Knowledge and Attitudes Questionnaire was used. The pilot study used in developing this instrument elicited responses from a sample of convenience consisting of 20 registered nurses employed within the Intensive Care and Coronary Care Units of a large Midwestern medical center.

Thornburg used a panel of experts selected from nursing, sociology, and psychology in establishing the content validity of the instrument, and knowledge and attitude portions of the instrument were tested for internal consistency. Data were factor-analyzed to establish construct validity for the knowledge and attitude portions of the instrument. Only questions with a factor loading greater than .51 were retained. Likewise, Cronbach alpha reliability coefficients were obtained in determining internal consistency of each subscale obtained from factor analysis.

Factors and corresponding alpha coefficients for knowledge questions included knowledge of the NDE (.84), causes/correlates of the NDE (.77), concomitant events/activities associated with NDEs (.72), and knowledge about persons' perceptions (.72). Factors and alpha coefficients for questions regarding attitude toward NDEs included reporting NDEs (.90), factors influencing/affecting care (.70), psychological implications of NDEs (.80), and patient care activities surrounding NDEs (.73). Factors and alpha coefficients for questions regarding attitudes toward care of clients included importance of nurses' attitudes to patient care (.92), patients' perceptions of their NDEs (.76), and nurses' awareness of the effect of NDEs on patients (.70).

Minor modifications in the original instrument made it easier to code and more applicable to clergy. The first of these modifications included relabeling each set of questions by section for further clarification. Questions also were added that pertain to the subjects' exposure to near-death experiences among parishioners, subjects' exposure to close friends and family who have reported an NDE, subjects' active involvement in counseling parishioners, number of hours per week spent counseling parishioners, religious affiliation, and geographic loca- 
tions. The modified instrument used in this study consisted of 7 general information questions, 18 cognitive questions, 17 affective questions, 15 professional questions, and 8 demographic questions.

General knowledge and information items included open-ended questions for additional clarification and questions requiring a "yes" or "no" response. Specific knowledge items were presented in a format requiring a "true," "false," or "undecided" response. Correct responses were given a numerical value of one, and incorrect or undecided responses were scored as zero.

Attitude questions were composed of positive and negative statements related to near-death phenomena and care of near-death experiencers as parishioners. Respondents chose from a range of responses including "strongly agree," "agree," "uncertain," "disagree," and "strongly disagree." Each response was given a number value of from one to five, with positive responses, as determined by Thornburg, scored so that an answer of "strongly agree" was assigned a value of five, and negative responses scored so that an answer of "strongly disagree" was assigned a value of one. Assignment of "correct" responses to knowledge questions, and "positive" and "negative" labels to attitude questions, followed the scoring procedure used by Thornburg in her original instrument (1988).

\section{Data Collection}

Permission was obtained from the Office of Protection of Human Subjects at The Pennsylvania State University to survey the selected sample population. The instrument was mailed to 2,722 clergy in the selected eight counties of Illinois and Pennsylvania. A cover letter, instrument, and self-addressed return envelope were provided for each participant. The cover letter explained the purpose of the study, the estimated time to complete the questionnaire, a requested deadline date, and instructions on returning the self-addressed stamped envelope and postcard. The participating subjects' names were not identified in any way, so confidentiality and anonymity were assured. The respondents were asked to write to the research team if they would like to obtain the results of the study. A reminder postcard was sent to subjects two weeks after the first mailing.

\section{Analysis}

Data were analyzed using the Statistical Analysis System (SAS). Measures of central tendency and variability were used to analyze normality of distribution of variables. A Pearson product-moment cor- 
relation coefficient was used to analyze correlations between knowledge and attitudes toward the NDE, personal experience with the NDE, and exposure to others' experience with the NDE. Likewise, a Pearson product-moment correlation coefficient was used to analyze the correlation between total knowledge score and total attitude score. ANOVA with Duncan and Tukey t-tests were conducted to compare the relationship of knowledge and attitude toward the NDE and geographic location. Likewise, other factors such as gender, educational background, and religious denomination were considered.

\section{Results}

\section{Respondents}

A total of 320 usable questionnaires were received, for a response rate of $12 \%$. Of the participating sample, $90 \%$ were males and $10 \%$ were females. The majority of respondents had earned a Master of Science degree (67\%), $10 \%$ had earned a Bachelor of Science degree, $8 \%$ had a Doctor of Philosophy degree, and the remainder reported "other." Fifty-eight percent were from Pennsylvania, with $48 \%$ from urban areas and $10 \%$ from rural areas. Forty-two percent of the respondents were from Illinois with $33 \%$ representing urban counties and $9 \%$ representing rural counties.

Approximately $98 \%$ of the clergy surveyed had heard of near-death experiences and nearly $48 \%$ had counseled parishioners who had an NDE. Approximately $10 \%$ of the clergy surveyed reported having had an NDE. Clergy who indicated having had an NDE were asked to describe that experience in their own words. These descriptions were then compared to Raymond Moody's (1975) 15 elements constituting a "core" near-death experience. Of the $10 \%$ reporting an NDE, only $61 \%$ reported one or more of Moody's (1975) elements. Twenty-six percent reported at least one element, $16 \%$ reported at least two elements, $10 \%$ reported at least three or four elements, and 39\% reported none of the elements.

Approximately $48 \%$ of the clergy surveyed reported that they had counseled parishioners who had an NDE and nearly $41 \%$ knew a close family member or friend who had an NDE. Nearly $47 \%$ of the clergy surveyed reported that they felt they should listen attentively to any NDE report and allow the parishioner to complete his or her story. Likewise, nearly 50\% reported that they would attend an NDE program. 


\section{Factor Analysis}

In the current investigation, a factor analysis of the Thornburg questionnaire was conducted to establish construct validity for the knowledge and attitudes portions of the instrument. Only questions with a factor loading greater than .40 were retained. Likewise, Cronbach alpha reliability coefficients were obtained in determining internal consistency of each subscale obtained from factor analysis. Factors and corresponding alpha coefficients for knowledge questions included characteristics of the near-death experiencer (.71) and descriptions of the NDE (.57). Factors and alpha coefficients for questions regarding attitude toward NDEs included importance of NDEs (.81) and psychological implications of NDEs (.68). All of these subscales showed acceptable levels of internal consistency.

\section{Knowledge}

The mean score for the total knowledge scale was 7.8 out of a possible 18 , with a range from 0 to 15 . Respondents were most knowledgeable about questions dealing with the NDE element of "peace," survivor's greater appreciation for life, and the powerful effect on the experiencer's belief in an afterlife. In their written descriptions of NDEs, respondents identified an out-of-body experience most often. Respondents were least knowledgeable about questions dealing with the relationships between attempted suicide and the NDE and the relationships between illness and accidents and the NDE.

While the majority (98\%) of clergy reported that they were familiar with the term NDE, many mentioned only one of the 15 elements described by Moody (1975) in their written description of NDEs. Considering the limited content of respondents' written descriptions of NDEs and their mean knowledge score (7.8), it appears that although respondents were familiar with the term NDE, they may lack a comprehensive understanding of the topic.

There was a nonsignificant $(0.13)$ trend suggesting an association between the total knowledge score and educational background. According to the Duncan test, there may be two groups that are distinct: "Other" and "B.S., M.S. or Ph.D." The mean total knowledge scores for clergy with a B.S. degree was 8.0, for an M.S. 7.7, for a Ph.D. 7.2, and for "other" 8.5. According to the Duncan test, when the score on the knowledge scale that dealt with characteristics of the NDEr was compared with educational background, a statistically nonsignificant (.13) 
trend was noted. Those with a B.S. or "other" degree had the highest mean score (4.35 and 4.35), followed by those with an M.S. (3.88). Those with a Ph.D. had the lowest mean score (3.46). (See Table 1.)

A Pearson correlation coefficient for the total knowledge score and variables related to NDE indicated that total knowledge score was significantly related with having heard of the NDE $(\mathrm{r}=.36, \mathrm{p}=$ $0.0001)$, having an NDE $(r=.23, p=0.0001)$, having counseled parishioners who had an NDE $(r=.21, p=0.0002)$, and having a friend or family member who had had an NDE $(r=.18, p=0.004)$.

\section{Attitudes}

The mean score for the total attitude scale was 49 out of a possible 85, with a range of 32 to 62 . Higher scores represented more positive attitudes toward near-death phenomena.

For the attitude subscale dealing with importance of the NDE the Tukey test indicated a significant difference $(.05)$ between the scores of males and females such that females had a more positive attitude (mean $=17.13)$ toward NDES than males (mean $=14.97)$. The Duncan and Tukey tests indicated a nonsignificant (.09) difference between females and males on the attitude subscale dealing with psychological implications of NDES such that females had a more positive attitude

\section{Table 1}

Mean Scores on NDE Knowledge and Attitudes

Scale Factors and Educational Level

\begin{tabular}{lccccc}
\hline & $\begin{array}{c}B . S . \\
(n=31)\end{array}$ & $\begin{array}{c}M . S . \\
(n=205)\end{array}$ & $\begin{array}{c}\text { Ph.D. } \\
(n=24)\end{array}$ & $\begin{array}{c}\text { other } \\
(n=48)\end{array}$ & $F$ \\
\cline { 2 - 6 } & & & & & \\
$\begin{array}{l}\text { Knowledge factors: } \\
\begin{array}{l}\text { Characteristics of } \\
\quad \text { NDErs }\end{array}\end{array}$ & 4.35 & 3.88 & 3.46 & 4.35 & 0.13 \\
$\begin{array}{l}\text { Description of the NDE } \\
\text { Attitude factors: }\end{array}$ & 3.65 & 3.77 & 3.71 & 4.17 & 0.30 \\
$\begin{array}{l}\text { Importance of the NDE } \\
\begin{array}{l}\text { Psychological } \\
\text { implications of the }\end{array}\end{array}$ & 15.94 & 14.94 & 15.21 & 15.58 & 0.78 \\
$\quad$ NDE & 12.16 & 12.18 & 12.42 & 12.10 & 0.90 \\
\hline
\end{tabular}




\section{Table 2}

Mean Scores on NDE Knowledge and Attitudes

Scale Factors and Gender

\begin{tabular}{lccc}
\hline & Male & Female & $F$ \\
\cline { 2 - 4 } & & & \\
Knowledge factors: & 3.98 & 4.26 & 0.43 \\
Characteristics of NDErs & 3.80 & 3.81 & 0.97 \\
Description of the NDE & & & \\
& & & \\
Attitude factors: & 14.97 & 17.13 & 0.05 \\
Importance of the NDE & 12.15 & 12.68 & 0.09 \\
Psychological implications of the NDE & & &
\end{tabular}

toward the NDE (mean $=12.68)$ than males (mean $=12.15)$. (See Table 2.)

Religious affiliation was significantly (.03) related to the attitude subscale that deals with importance of NDEs, with Eastern faiths scoring the most positive score (mean $=21$ ), followed by "other" (mean $=16.11)$, Catholic $($ mean $=15.6)$, Protestant $($ mean $=15.12)$, Jewish (mean = 9.3), and Agnostic (mean = 5.0). (See Table 3.)

A positive correlation was found between knowledge scores and attitude scores of all respondents $(\mathrm{r}=.21, \mathrm{p}=0.0002)$.

\section{Discussion}

Based on the analysis of these data and the comments of the respondents, participating clergy demonstrated limited knowledge of the near-death experience; however, in general, they had a moderately positive attitude toward the subject. Data may have been influenced by confusion about the exact definition of "near-death experience." Many clergy described "near-death experience" in terms of any situation in which death may have been imminent versus the descriptive elements used by Moody (1975).

Based upon subjective comments, there was a wide range of feelings expressed toward the NDE. These comments ranged from curiosity and fright to fascination, doubt, questioning, and disinterest. Nevertheless, many clergy indicated an interest in obtaining more information about the NDE. Many respondents (47\%) felt that they had a responsibility to parishioners to listen attentively to their accounts of the NDE and 


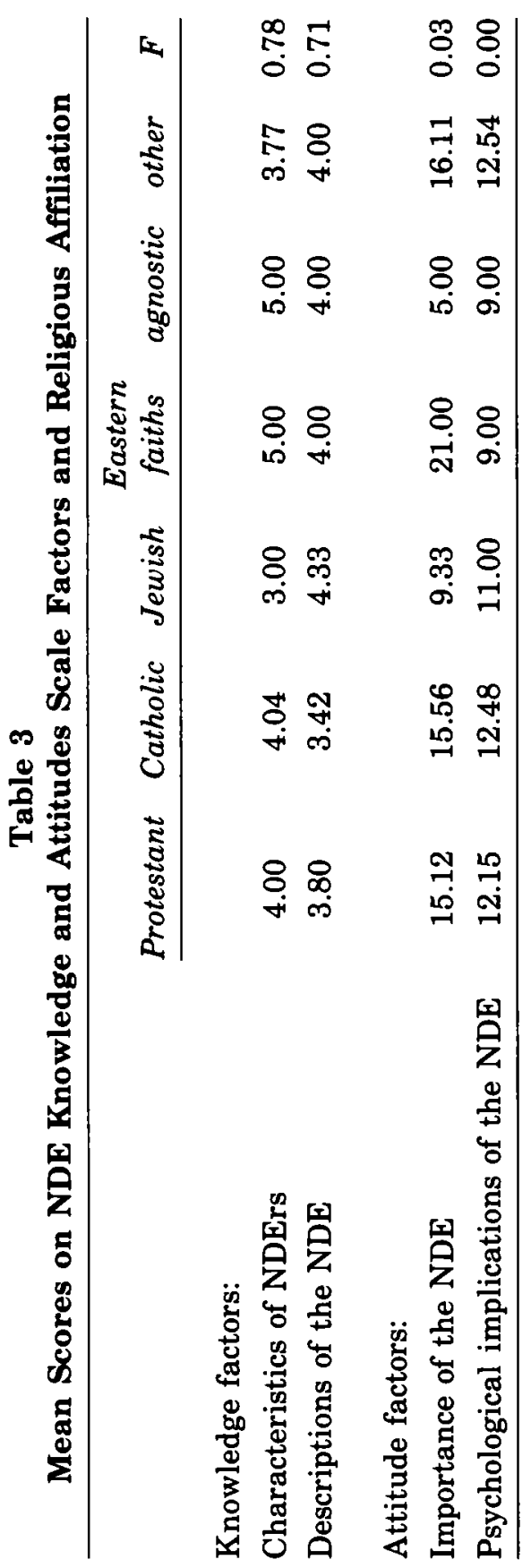


nearly $50 \%$ of the clergy surveyed indicated that they would attend a program on the NDE. Royse (1985) reported that experiencers tend to become more religious after having a near-death experience. Royse (1985) also reported that although the majority of his clergy respondents felt that NDEs were not in conflict with Biblical teachings, only a quarter of them introduced the topic when counseling parishioners. This may suggest that pastoral counselors are hesitant to introduce the topic of NDEs. Royse (1985) indicated that pastoral counselors who are not open-minded on the subject of the NDE are likely to communicate this to parishioners by body language, remarks, or questions, and thus suppress the sharing of a highly significant event in the parishioners' lives. Quite often it is difficult for the NDErs to relate to others their perceptions and emotions about the NDE, perhaps out of fear of being thought crazy. Given both the frequency and the profound effects of NDEs, clergy need to attempt to learn more about the topic in order to help meet the NDEr's needs. Considering that an estimated eight million Americans have experienced NDEs, and in light of the fact that nearly $48 \%$ of the clergy surveyed in this study reported that they have counseled parishioners who have had an NDE, the potential for clergy exposure to the phenomena is high. Thus, the topic of NDEs should warrant educational involvement within the existing educational and professional preparation programs for clergy in all areas, including but not limited to program development, classes, workshops, and professional consultation. Integrating and "normalizing" the phenomena within existing educational and professional preparation programs may facilitate meeting the near-death experiencer's emotional needs.

\section{References}

Moody, R.A., Jr. (1975). Life after life. Covington, GA: Mockingbird.

Ring, K. (1982). Near-death studies: A new area of consciousness research. Storrs, CT: International Association for Near-Death Studies.

Ring, K. (1984). Heading toward omega: In search of the meaning of the near-death experience. New York, NY: William Morrow.

Royse, D. (1985). The near-death experience: A survey of clergy's attitudes and knowledge. Journal of Pastoral Care, 39, 31-42.

Thornburg, N.R. (1988). Development of the Near-Death Phenomena Knowledge and Attitudes Questionnaire. Journal of Near-Death Studies, 6, 223-239. 